\title{
¿Cuánta política encierra lo personal? Notas sobre género y violencia doméstica contra las mujeres.
}

\author{
Concepción PAZO GANDARA \\ Instituto de Medicina Social/Universidade Estadual do Rio de Janeiro \\ conchitapazo@oi.com.br
}

Recibido: 15.09 .2012

Aceptado: 30.09.2012

\section{RESUMEN}

En los estudios sobre violencia doméstica contra la mujer, la atención hacia las experiencias subjetivas de las mujeres se ha materializado en discursos científicos y prácticas e intervenciones sociales. En este artículo se ha intentado avanzar más allá de la noción de patriarcado al incorporar al estudio de la violencia nociones de las ciencias sociales que conceptualizan el género como categoría relacional e histórica que opera a través de la intersección con otras categorías. Para ello se analizaron las entrevistas de dieciocho hombres y diecisiete mujeres involucrados con la ley que rige en Brasil los crímenes de violencia contra la mujer. Se identifican y se discuten algunos temas como la victimización, la denuncia de la agresión y el proceso de escape de la relación violenta.

Palabras Clave: violencia contra la mujer, relaciones de género, victimización, denuncia

\section{How Political is the Personal? Notes on Gender and Domestic Violence against Women.}

\begin{abstract}
In studies on domestic violence against women attention to subjective experiences of women has resulted in scientific discourses and social practices and interventions. In this essay we move beyond the notion of patriarchy by including in our study of violence concepts of the social sciences that conceptualize gender as a relational and historical category that operates through the intersection of other categories. To achieve this aim, we analyze the interviews of eighteen men and seventeen women involved with Brazilian laws that regulate crimes of violence against women. We identify and discuss some topics such as victimization, the report of an aggression, and the process of escaping a violent relationship.
\end{abstract}

Key words: violence against women, gender relations, victimization, denunciation

\section{INTRODUCCIÓN A CONCEPTOS Y CONTEXTOS DEL FEMINISMO Y DE LA "VIOLENCIA DOMÉSTICA CONTRA LA MUJER"}

Desde la llamada segunda ola del feminismo, el movimiento de mujeres ha impulsado cambios en las relaciones de género tradicionales, que solían atribuir 
mayor valor social y poder a los hombres. Estos cambios se han traducido en logros jurídico-legales implementados como políticas públicas con vistas a la emancipación femenina y a la igualdad de derechos entre hombres y mujeres. "¡Lo personal también es político!" y "iQuien quiere, no mata!" se convirtieron en las consignas del feminismo en Brasil. Se ha denunciado la condición de la mujer en la intimidad, que se ha visto que es la base de los conflictos y de la violencia en la familia. Las desigualdades de género también tenían un lado doméstico, privado, subjetivo y único.

¿Qué quieren decir las feministas con "lo personal es político"? Quieren decir, primeramente, que lo que ocurre en la vida personal, particularmente, en las relaciones entre los sexos, no es inmune a la relación, a la dinámica de poder, que ha sido vista típicamente como la faz distintiva del mundo público y del político. Y también quieren decir que, ni el espacio de la vida doméstica, personal, ni el de la vida no-doméstica, económica y política, pueden ser interpretados, aisladamente uno del otro. Por lo tanto, tal como Carole Pateman (1983) escribió, pensar si el Estado puede elegir entre intervenir o no en la vida familiar no tiene ningún sentido; la única cuestión comprensible es cómo el Estado, al mismo tiempo, define e influye en la vida familiar.

La cuestión de cómo el Estado, a través de su aparato jurídico, debe intervenir en los conflictos de la intimidad se convirtió en un foco de debates entre feministas y legisladores (Debert y Gregori, 2008). Al convertir la política en cuestión pública y privada, la confluencia de los movimientos feministas en los campos de la salud y del derecho pusieron en el centro de atención las experiencias subjetivas de las mujeres, valorando las emociones, las interacciones afectivas e íntimas, con sus tensiones y violencias, como cuestiones relacionadas con el conocimiento científico, y la posibilidad y la necesidad de intervenciones sociales específicas (Schraiber et al., 2009).

Este trabajo se posiciona junto a tantos otros que buscan entender la complejidad de las relaciones íntimas violentas con el fin de contribuir a la mejora de las políticas estatales de prevención y asistencia a mujeres y hombres involucrados en casos de violencia. En lugar de exponer la trayectoria de los estudios feministas en la construcción de la categoría de "violencia contra la mujer", me interesa contextualizar la ruptura del consenso por considerarla sólo como un fenómeno resultante del patriarcado (Gregori, 2010; Soares, 2009, 2012). La incorporación de

Sistema patriarcal o patriarcado es un concepto ampliamente utilizado por feministas de diversas corrientes y que resumo como el "gobierno/autoridad del padre". Se trata de una manifestación y de la institucionalización del dominio masculino sobre las mujeres, caracterizado por la autoridad ejercida por hombres e instituciones (por ellos dirigidas) sobre las mujeres y la unidad familiar. A pesar de este sistema haber sufrido progresivas contestaciones en los últimos cincuenta años en la sociedad contemporánea 
la categoría de género a las ciencias sociales hizo posible expandir las interpretaciones del fenómeno, en la medida en que debería ser entendida como categoría relacional e histórica (Scott, 1990).

La "deconstrucción" del binario masculino-feminino ha posibilitado, en última instancia, que las mujeres pudieran ser investigadas a partir de sus relaciones con las estructuras sociales de las cuales forman parte, no teniendo en cuenta una perspectiva esencialista o de victimización de la mujer, como era común en las investigaciones hasta que la categoría de género se incorporó a las disciplinas de las ciencias sociales. Otro cambio que la introducción de este concepto ha permitido ha sido que los hombres se convirtieran también en sujetos de investigación, desnaturalizando sus estereotipados papeles de verdugos/agresores.

A pesar de la introducción de esta categoría de análisis tan marcadamente relacional -y que luego se ha ampliado, conceptualmente, su vinculación a otras categorías con el fin de interpretar mejor los fenómenos sociales desde una perspectiva de la llamada interseccionalidad (Davis, 2009)-, la suposición dominante de las conexiones entre la violencia contra las mujeres, y las relaciones de género sigue siendo la violencia causada, principalmente, por la dominación masculina.

El sesgo relacional de género, subsumido en el sesgo del patriarcado como perspectiva privilegiada de análisis del fenómeno de la violencia contra la mujer, en especial en la pareja, deja fuera los múltiples factores que contribuyen a la generación de comportamientos violentos: los aspectos históricos e idiosincrasias de cada individuo y de la propia relación, las distintas maneras de ejercer el poder y la resistencia, presentes en todas las relaciones de pareja, las insatisfacciones y conflictos personales, que traspasan en grados variados cualquier relación amorosa, las desigualdades físicas, los contextos sociales, así como las herramientas formales e informales de contención de la violencia (Soares, 2012). Minimizar la importancia de las relaciones de género vistas desde el patriarcado, por otro lado, puede significar que se pierde de vista un elemento axial en la comprensión de una parte de las manifestaciones de la violencia doméstica, a saber, aquella estructurada en el ejercicio de poder y control de una persona en relación a la otra, lo que por mucho tiempo ha sido de facto y de derecho privilegio masculino.

A pesar del énfasis en este factor el patriarcado ha alimentado la dicotomía inocente/culpable, fijando una oposición entre la víctima/mujer y el verdugo/hombre en las relaciones de pareja. Varias autoras (Gregori, 2010; Suarez y Bandeira, 2004; Soares; 2009, 2012), aunque no sugieren ninguna inversión de estas posiciones entre hombres y mujeres, proponen una causalidad más dinámica para la violencia entre

occidental, las feministas consideran importante mantener como eje central de lucha la resistencia a la hegemonía de este poder. Las políticas brasileñas de combate a la violencia de género utilizan este concepto para las justificaciones de sus propuestas. 
compañeros íntimos. Estas investigadoras creen que la pareja, en sus múltiples interacciones y planos de experiencia, realiza una "operación combinatoria particular" (Gregori, 1993: 93), de manera más o menos conflictiva/violenta, en que patrones distintos de comportamientos y conductas de género tienen que ser repactados entre los cónyuges a lo largo del matrimonio.

No se trata de dejar sin castigo a los autores de las agresiones, sino de afinar las herramientas de observación y escucha para establecer diferenciaciones que puedan conducir hacia un análisis de las situaciones que apunte cuáles de ellas exigen una intervención inmediata de la justicia criminal; medidas de naturaleza psicoterapéutica o de mediación de conflictos.

Admitiendo la necesidad de una investigación que pueda abordar el fenómeno de la violencia en las relaciones íntimas ${ }^{2}$ en sus formas más complejas y dinámicas, este trabajo tiene como objetivo contribuir a la comprensión de las desiguales formas y normas que esta violencia presupone para hombres y mujeres y establecer diferenciaciones más consistentes y más de acuerdo con la complejidad de los hechos empíricos.

\section{LECTURA DE LOS DATOS DE INVESTIGACIÓN: SIGNIFICADOS DE LA VIOLENCIA DE PAREJA PARA HOMBRES Y MUJERES.}

Llevé a cabo entrevistas con dieciocho hombres denunciados por sus parejas como autores de violencia, y diecisiete mujeres que buscaron ayuda en instituciones públicas de asistencia en los campos jurídico, psicológico y social. En el análisis primario de los datos de la investigación he identificado y tematizado los significados que ambos atribuyen a sus experiencias de violencia íntima.

En este trabajo me detendré en el análisis de las entrevistas a partir de la elección de dos categorías que se entrecruzan, demarcando distintas formas de percepción de la experiencia de la violencia de pareja para hombres y mujeres. La primera es el hecho de la denuncia de la violencia, o sea, cómo la expresan y la cualifican, y cómo comprenden sus motivaciones y sus consecuencias. La segunda categoría tiene que ver con cómo cada uno justifica la reclamación de su cota de victimización en el

\footnotetext{
${ }^{2}$ Hay una variabilidad inmensa de nombres para la violencia que ocurre entre hombres y mujeres que refleja la dificultad de delimitar las fronteras y las posiciones ocupadas por los sujetos de los sucesos violentos. Violencia contra la mujer, violencia de género, violencia de pareja, violencia machista, violencia doméstica, violencia familiar, violencia conyugal, violencia en las relaciones intimas son algunos de los nombres utilizados por feministas, investigadores(as) y legisladores(as) brasileños(as). En este artículo utilizo algunos de estos términos para referirme a la violencia que ocurre entre hombres y mujeres que tienen o tuvieron relaciones erótico-afectivas.
} 
conflicto $\mathrm{y}$, por consiguiente, la reivindicación de resarcimiento de pérdidas o atenuación de la criminalización.

He identificado las circunstancias más comunes que mujeres y hombres atribuyen a la irrupción de la violencia, así como la narración de sus posicionamientos y los de su pareja en la trama relacional. Los celos, la bebida y el "machismo" fueron las causas atribuidas por las mujeres, mientras que los hombres se quejaban de que ellas se "metían indebidamente en sus vidas", sea a través de constantes provocaciones o severas críticas. Ambos se posicionaban como víctimas y justificaban o reclamaban para sí derechos legales. Las mujeres, en general, argumentaban que la denuncia había sido la última carta en la búsqueda de una solución para las agresiones, creyendo que habían hecho de todo para que el matrimonio fuera lo mejor posible para ella y sus hijos. Unas decían que no querían que sus parejas fueran procesadas, ni mucho menos encarceladas, pero que sí, que sentían más amparo bajo la justicia. Los hombres, en general, decían sentirse traicionados por las mujeres, porque éstas también habían sido violentas en las relaciones y jamás denunciadas, ya que según algunos de ellos " los problemas de casa se resuelven en casa". Para las mujeres, los hombres no sabían lo que era el amor ni la responsabilidad, además de que les parecían muy propensos a la bebida. Muchos eran "patologizados" e incluso disculpados por las propias mujeres, a causa de una infancia que, como para muchas de ellas, había sido desgraciada. Para los hombres, las mujeres eran débiles moralmente, neuróticas y extremadamente celosas, y presentaban una imagen sombría de la eterna insatisfecha e interesada en los beneficios provenientes de los esfuerzos e ingresos de ellos.

La victimización se presenta de distintas formas también para los dos. Las mujeres no siempre siguen un itinerario convencional de pasividad inerte. Ellas, mientras acumulan situaciones victimarias en su trayectoria conyugal, construyen también vías de salida de la situación. La denuncia funciona muchas veces como toque de atención inicial para la búsqueda de una solución a sus conflictos conyugales, que va desde la sugerencia o el consejo de distintas posibilidades de renegociación de un nuevo pacto conyugal, acordados frente a la autoridad jurídica a través de la promesa de regeneración del acusado (tratamientos psicológicos, Alcohólicos Anónimos, grupos de reflexión, religión), hasta separaciones no amigables, pero amparadas por la justicia.

La victimización femenina observada más bien aparece unida a otra categoría que yo llamaría "sacrificio virtuoso de la mujer". En esta categoría se aglutina todo lo que tiene que ver con sentimientos como el perdón, la esperanza, la comprensión; así como también con valores asociados a la maternidad, como caridad, fraternidad, es decir, todas estos sentimientos que las mujeres tendrían, y que estarían vinculados a algo que, cuando es descrito por ellas en las entrevistas, parece quedar en el plano biológico o esencial. Sin embargo, fue interesante percibir también que muchas 
mujeres que enaltecían la posición de una maternidad sacralizada y un yo sacrificado en su nombre eran capaces de soportar agresiones verbales y físicas de las parejas/padres hacía sus hijos. En general, la violencia doméstica contra la mujer se desarrolla o se produce en medio de la violencia familiar, donde los hijos se hallan también afectados por las situaciones de miedo y agresiones que experimentan. Incluso siendo tan poderoso este arquetipo de la maternidad virtuosa, frecuentemente, no es suficiente para desencadenar una separación. Parece que, en muchas situaciones, el estereotipo de género como la maternidad y la bondad quedan subsumidos a otro que es el de la "vacilación femenina".

Las feministas se preguntaban, desde los tiempos pioneros de la década de los sesenta, por qué las mujeres permanecían tan largos periodos en situaciones dramáticas de violencia y se resistían a denunciar a sus parejas, justificándose, en muchos casos, en un presunto vínculo afectivo con las mismas. La cuestión permanece viva hoy en día, aunque, sin embargo, ha sido ampliada a cuestiones como: ¿cuales son los elementos individuales, interrelacionales y sociales que dificultan la transformación de las situaciones de violencia, bien sea a través de separaciones o atenuaciones de los conflictos? (Muszkat, 2003). Esta ampliación resulta también, en gran medida, de la negación de las investigadoras a mantener interpretaciones acerca de la vacilación femenina sobre el eje de la victimización y la pasividad.

De forma distinta, la victimización del hombre se desarrolla en el campo de la ingratitud y la injusticia. Según el punto de vista masculino, las mujeres solo querían aprovecharse de ellos mientras servían a sus planes, olvidándose de todo lo hecho por ellos hasta entonces, en el momento de la denuncia, que es sentida como una traición.

La legislación ${ }^{3}$ de lucha contra la violencia de pareja en Brasil, al querer hacer justicia a favor de las mujeres, estaría quitando la voz a los hombres e imputándoles la identidad de agresores. Reivindican una ley propia con la que puedan también defenderse de las agresiones de las mujeres. Admiten, sin embargo, que no se imaginan llegando una comisaría de policía para presentar una denuncia contra su pareja por malos tratos. Esta posición de "víctima total" los acercaría en demasía a una posición femenina que ellos mismos no se permitirían asumir.

Por cuestiones metodológicas inherentes a la extensión de este artículo he preferido, en vez de presentar fragmentos de diversos relatos y realizar la

\footnotetext{
${ }^{3}$ La ley que rige en Brasil los crímenes de violencia doméstica y familiar contra la mujer se denomina, ley María de la Peña, en homenaje a una víctima de esta violencia que quedó parapléjica, debido a un intento de homicidio por parte de su ex-marido. Esta es una ley popular y polémica, tanto por las innumerables noticias de los medios nacionales, como porque actores, actrices y jugadores de fútbol han estado involucrados en escándalos en relación a ésta. Dado el límite de extensión de este artículo, no podré extenderme, presentando las discusiones de legisladores y feministas sobre la ley.
} 
correspondencia con las categorías arriba citadas, elegir un caso entre las mujeres, y otro entre los hombres que me parecieron pertinentes para las conclusiones preliminares que se desprenden del material de las entrevistas.

\section{UNA MUJER: DENUNCIA, VICTIMIZACIÓN Y CAMBIO.}

Soraya $^{4}$, como voy a llamar a la usuaria que he entrevistado, tenía 64 años cuando buscó la institución pública, llamada Centro de Referencia de la Mujer, después de haber denunciado a su ex-marido por delitos de violencia y entrado con la demanda de divorcio en el juzgado de familia. Ella relata una vida conyugal de más de cuarenta años marcada por actos de violencia física, moral y sexual. Desde que está separada y frecuenta este Centro de Asistencia se encuentra mejor y no le importa conceder entrevistas a los medios locales para hablarles acerca de su trayectoria conyugal violenta y de cómo se liberó de ella.

Con respecto a la historia de su vida cuenta que había sido una chica "criada en cautividad" contraponiéndose a las chicas "criadas en libertad", expresiones que en Brasil se refieren al grado de liberación sexual en que una chica es socializada dentro de los limites que establece la regulación familiar sobre su sexualidad. Soraya hablaba acerca de la diferencia entre la crianza de ella y la de sus dos hermanos mayores: "ellos iban a todos los sitios que querían junto con las otras chicas que eran chicas criadas en libertad (...) pero yo no fui criada así. Yo me he casado virgen, con velo y guirnalda, ¿qué te parece?"

Su única rebeldía fue casarse con su primer novio, un chico "de color", amigo de sus hermanos, y cuyo noviazgo no era aprobado por sus padres no tanto por su color, tal y como ella misma me comentó, como por su carácter irascible y con tendencia al alcoholismo. No se había rebelado para salir con amigas o estudiar, pero sí para casarse con aquel de quien creía estar enamorada. El amor surgía como motor para la salida de la opresión y era la mayor prueba de expresión de una individualización irreemplazable. Según me dijo, durante el noviazgo, algunas cosas ya no le gustaban del carácter del novio, pero no hizo caso, pensando que el amor todo lo cambiaría.

Meses después de casarse, en la primera Navidad, "las confusiones" empezaron. La irrupción, los motivos y las características de "las confusiones", como llamaba a las violencias vividas eran así descritas:

\footnotetext{
${ }^{4}$ Por no cargar el texto en demasía, no repetiré a lo largo del artículo que todas las informaciones presentadas, incluso las que no están entre comillas, son retiradas de las conversaciones con los sujetos de investigación. La utilización de las comillas en palabras sueltas en el texto tiene la intención de hacer hincapié en algún término específico dicho por los entrevistados y que me ha parecido importante mantenerlo.
} 
"Se emborrachaba, vaya! borracho de caerse, así quedaba, imagínate, no podía coger un vaso. Cogía una copa, y i hala !, entonces, ya tenía un motivo para decir lo que le diese la gana, bebía para poder insultar, agredir con palabras. No he llegado a decirlo en la audiencia, pero una vez me golpeó en la cara. Fue bien al principio del matrimonio".

Sin experiencia y sin apoyo de los padres, decidió hacer bocadillos y otras comidas para vender en la calle, llegando a tener un pequeño y rentable restaurante gracias a sus dotes culinarias, simpatía y mucho trabajo. Pero esto, o sea, su supremacía financiera, no le fue suficiente como para hacerse independiente. La imagen que describía de la pareja era de un hombre perverso, que la había enclaustrado en casa vigilándola, haciéndola su esclava sexual ("bebía y me forzaba al sexo anal") y laboral ("trabajaba en casa y ponía todo mi dinero, sea comprando muebles, sea pagando más estudios para los hijos mientras él se quedaba en el bar"). Ella componía para sí misma una imagen de la virgen inexperta que intenta ineficazmente desenredarse de su vida conyugal, atrapada como estaba en sus miedos: "Pues desde el primer año de casada, yo ya quería salir de aquello. Quería quedar libre y él no me dejaba, decía: 'No. Tú no vas a estudiar. ¿Estudiar, para qué?'. Incluso sin entender porqué ella podía trabajar y no podía estudiar, dijo que se había acomodado a este orden. Hacía lo que había visto hacer a su madre, que no trabajaba fuera, pero se dedicaba al hogar, ahorrando y trabajando para el conjunto de la familia.

Ella justificaba su inmovilidad desde un punto de vista psicológico: "Él me tenía en sus manos, me decía: 'tú eres fea, tú no eres capaz, tú no eres buena en la cama. Mira, solo ahora sé lo que es el sexo bueno!". Al preguntarle sobre cómo todo se fue convirtiendo en insoportable, describe esta evolución negativa principalmente a partir de cuando supo que el hijo menor padecía trastornos mentales y que los médicos le dijeron que era debido a los "genes paternos". Por un tiempo, tuvo pena del marido y pensó que la caridad, que la religión le pedía cumplir dentro de casa. Pero la negación de él a someterse a tratamiento, y el descubrimiento de una amante fueron los detonadores de la denuncia y de la separación. Sin embargo, sería necesario tener pruebas para conseguir echarlo de casa, ella lo sabía, y "en el día de San Jorge, bajo su protección", ideó una situación de conflicto y violencia. Ella decía que sabía que "a él no se le podía contrariar; si se le contrariaba, aunque no hubiese bebido, se convertía en el demonio". Y contrariarlo fue la carnada utilizada. Cuando llamó a la policía y ésta cogió al marido en flagrante delito, rompiendo cosas en la casa e insultándola, empezó su proceso de separación. Ella, varias veces en su conversación, se refiere al hijo menor, enfermo, supuestamente, por culpa del padre, como pieza fundamental para su "rebeldía", pero insuficiente para exigir la separación que solamente se desencadenó con el descubrimiento de la amante. 
Recurrir a la Institución también tuvo mucho peso para el proceso de "rebeldía", sin embargo y aunque deseaba dejar la relación vacilaba:

"El miedo seguía después de la denuncia porque a pesar de tener detrás a todas las de aquí (se refiere a las técnicas de la institución), de sentirme fortalecida, de que la doctora (abogada de la institución) me dijera: 'sigue adelante, ¿no es esto lo que quieres?' Yo contestaba 'sí, es esto lo que quiero'. Todas me ayudaban, pero tenía todavía miedo".

Ella justifica su vacilación, así como su "rebeldía" de casarse con quien quiso, por amor y por enamoramiento que, a su vez, funcionaban como factores que no permitían una visión de la situación real:

"Me preguntaba muchas veces por qué él era de aquella forma: "Yo lloraba mucho delante de él. (...) Le hacía gracia verme así. A él le gustaba verme sufrir, le sentaba bien. (...) Yo estaba enamorada de él. Yo estaba cieguita. Pero solo he percibido esto con el paso del tiempo".

A partir de la denuncia y de la demanda de separación todo fue una lucha para Soraya: "Lo que quería era liberarme de él. Yo no quería dejarlo marchar con un montón de dinero. Mi objetivo era no permitir que quedase como un trofeo de la agresión".

La cuestión del "process of leaving"5(Anderson y Saunders, 2003), tan comentada en la literatura anglosajona, surge a lo largo de todo el relato de Soraya como algo que sucede poco a poco, con una lentitud increíble, configurándose como viable aunque lleno de miedos. La palabra proceso es muy pertinente por la cuestión del tiempo. Al mismo tiempo que siempre quiso separarse, la crianza de los hijos y el patrimonio adquirido tejían un entramado conflictivo de altos costos personales y familiares.

La separación es sentida como un retorno a ser una misma, alguien de quién se alejara por miedo y por falta de apoyo:

"Ahora vuelvo a ser quien era y dejé de ser con el matrimonio. Porque soy como quiero ser, lucho, hago, hago y nadie me manda nunca más. Este señor con quien estoy saliendo es cariñoso, pero no quiero vivir junto a él porque no sé cómo va a ser a partir del momento en que vayamos a vivir bajo el mismo techo.".

La última vez que he estado con Soraya, seguía siendo novia del mismo señor, vivía con el hijo enfermo y estaba haciendo cursos de artesanía. Me dijo que había

\footnotetext{
${ }^{5}$ En una traducción libre el proceso de dejar una relación de pareja violenta.
} 
llegado a un acuerdo patrimonial con el ex-marido, y se sentía feliz por vivir la vida de manera más autónoma y sin violencia.

\section{UN HOMBRE: DENUNCIA, VICTIMIZACIÓN Y CAMBIO.}

Adriano tenía 29 años cuando lo entrevisté, trabajaba como conductor de autobús y hacía pequeños servicios como fontanero y electricista en su tiempo libre. Tenía estudios medios incompletos, era protestante y vivía de alquiler. Es importante observar que la entrevista ${ }^{6}$ me fue concedida después de haber asistido a una audiencia en la cual fue acusado de violencia doméstica contra su mujer. En la audiencia, en la que yo estaba presente, el juez no le dejó hablar cuando quiso justificar su delito y le hizo reprimendas sobre su comportamiento pasado y advertencias en cuanto al futuro. Aunque mi intención fue convencerlo de que yo soy una investigadora y que no tengo ninguna relación profesional o influencia sobre los juristas, creo que esta condición puede haber influenciado el discurso de Adriano que, como será presentado con sus propias palabras, intenta minimizar su culpa y relativizar su papel de agresor, disputando con su ex-mujer la posición de víctima en la historia conyugal de ambos. Estas características están presentes en la mayoría de las narrativas de los entrevistados de mi investigación.

Al ser preguntado acerca del por qué de los conflictos de pareja, los atribuyó, principalmente, al carácter dudoso de su ex-mujer:

"Nosotros nos llevábamos bien. Sólo que, como toda relación, con el paso del tiempo la persona empieza a exigir. Marcia parece que no razona correctamente sobre las cosas que hace. (...) Yo conozco a su ex-marido y él me ha dicho que ella es una persona a la que nadie soporta en el barrio donde vivieron. Sólo que yo no la conocía bien. (...) Marcia es un tipo de persona que se hace la inocente. Cualquiera que la conozca se da cuenta. Ella es una persona cariñosa, cuidadosa, pero ella también provoca, ofende, se equivoca y se hace la segura, la lista."

Son muchas las situaciones de relativización de culpas y de des-identificación con la imagen del agresor, principalmente a través del fortalecimiento de la figura de hombre trabajador:

“(...) Yo tenía dos trabajos. Cuando la conocí, yo trabajaba en el ayuntamiento, conduciendo camiones desde las siete de la mañana a las cinco de la tarde, y de seis de la tarde a once de la noche como motorista de la empresa de autobuses. Llegué a casa y me mudé de ropa. Ella ya estaba acostada. Fui al baño muy de prisa porque estaba muy

\footnotetext{
${ }^{6}$ Las condiciones de las entrevistas con los hombres fueron prácticamente iguales, o sea, después de audiencias en las cuales no tuvieron oportunidad de hablar y aún escucharon reprimendas o críticas del juez.
} 
cansado y quería descansar. Con las prisas me dejé la luz de la habitación encendida. Una luz muy débil. Cuando volví, ella ya empezó a agredirme verbalmente diciendo: 'Que mierda Adriano! No te das cuenta de que estoy cansada, que voy a trabajar mañana y tu dejas esta luz encendida en mi cara!'. Sólo que yo también trabajaba por la mañana y me despertaba más temprano que ella. A pesar de estar siendo acusado de agresión por violencia, yo soy una persona que no vivo agrediendo a nadie, ni ofendiendo a nadie, ¿te fijas? Al revés. Soy una persona que para haber hecho lo que hice fue necesaria mucha presión. Yo soy una persona tranquila. Le dije entonces: 'Perdón. Olvidé la bombilla encendida porque estoy muy cansado. Mi cabeza no funciona de forma normal. No he tenido la intención de dejar la luz encendida para despertarte."

Fueron varios los adjetivos utilizados por Adriano para rebajar y despreciar a Marcia. Quería hacer ver que si su posición era la del agresor, la "víctima" tampoco era un ejemplo de moralidad; al revés, era alguien mucho peor que él.

"Ella no es una persona paciente. Ella no sabe sentarse y hablar. Con ella todo acaba en discusión. Ella te insulta por cualquier cosa.". "Ella es una persona calculadora, utiliza estrategias, crea situaciones para salir ganando. Frecuenta la Iglesia, pero no sabe qué va a buscar allí. No sabe perdonar a nadie, no sabe hacer nada por nadie. Solo sabe criticar, tener envidia, intereses. Ella siente envidia de las amigas y quiere exhibirse, quiere parecer mejor que los otros."

En el relato que sigue, Adriano contrasta su virtuosismo de trabajador incansable con la tendencia explotadora, egoísta e insatisfecha de la mujer, que lo agota y aniquila:

"Yo me he equivocado al golpearla, lo sé. Yo tenía sentimientos verdaderos por ella, pero no he logrado soportar lo que ella ha hecho conmigo. En el día de la agresión yo había estado trabajando desde las siete de la mañana cargando mucho peso a la espalda. (...) estaba trabajando para mejorar nuestras vidas. Yo le regalaba muchas cosas, pero nada estaba bien. Muchas veces no sabía qué hacer para pagar tantas cosas. Ella quería micro-ondas, quería esto, quería aquello, (...) era insoportable."

Adriano, al igual que las mujeres en situación de violencia de pareja en general, también se victimiza por una violencia sufrida. En su caso, la violencia en forma de exigencias materiales de la mujer lo convierte en su esclavo laboral. Él también, como Soraya, argumentaba que el amor y el trabajo todo lo cambiarían:

"Como yo la quería mucho, intentaba creer que al trabajar mucho para mejorar en la vida, todo esto cambiaría, ella mejoraría. En cuatro meses juntos, peleamos todas las semanas. O mejor, ella peleaba conmigo por algo, pero yo no peleaba con ella para nada". 
En su discurso, Adriano hacía hincapié en la oposición del hombre racional y coherente con la mujer inconsecuente, irascible e hiriente. Parecía querer hacerme ver que la agresión hacia su mujer había sido fruto de la presión que ella provocaba. La pelea que desencadenó la agresión empezó a causa de una mentira que Adriano le dijo a Marcia con el fin de "evitar discusiones", pero que se había convertido en el centro del conflicto. Él decía que Marcia era muy celosa y que no le gustaba que frecuentara el barrio donde vivía una antigua novia suya. Pero él tuvo que ir allí a causa de su trabajo y ella lo descubrió, lo insultó llamándole mentiroso y cosas peores. Él justificaba la mentira proyectando la culpa en Marcia, que lo "obligaba" a mentir. El descubrimiento de la mentira fue el combustible para que ella lo acusara de mentiroso. En la discusión ella lo golpeó y lo arañó en los brazos. En palabras de Adriano: "Yo le pedí que parara, pero cuando ella empezaba una discusión, hasta que no conseguía ponerte rabioso no paraba. Ella tenía que hacerte sufrir." Lo que desencadenó el golpe, o sea, lo que fue insoportable se describe así:

"Ella me miró a los ojos y dijo que el hombre de su vida había sido su ex-marido del que nunca debería haberse separado. Fue justo en ese momento; yo levanté la mano y le di un golpe en mitad de la cara. Pero ella no cuenta todo esto, ¿verdad? Le dijo al juez que me golpeó para defenderse, yo puedo haber perdido la cabeza, pero ella no cuenta que antes de haberle levantado un dedo, ella me había dado un golpe en la cara."

En la narrativa de Adriano la relativización de su culpa corre paralela a con un proceso de victimización. Los hilos de estas dos categorías mezclan ataques morales a las conductas y aspectos de la personalidad de la ex-mujer, que para él se hace la inocente y la víctima, con la construcción de una imagen de sí mismo como hombre pacífico y trabajador. Un último hilo de este entramado al que él intenta agarrarse se refiere a la ley María de la Peña, que estaría permitiendo la injusta cristalización de posiciones de víctima y agresor, respectivamente, para mujeres y hombres, dejando estos últimos en una posición indefendible:

"Mira, en momento alguno va ella a admitir que también cometió errores para que yo llegara a este punto (a agredirla). En momento alguno va ella a recordar que me humilló, me pisó, me golpeó la cara, me arañó. (...) La mujer cuando es comparada con el hombre, todo el mundo lo sabe, e incluso está en la Biblia; la mujer es una jarra frágil, es más frágil que el hombre. La mujer es frágil en fuerza. Y hasta su cabeza es más débil. Mi mujer, por ejemplo, tenía la cabeza mucho más débil que la mía. Para entender cualquier cosa, ella era más débil, mentalmente, que yo. Entonces es esto que te cuento. La ley se hizo para esto, para proteger al más débil. Ha protegido a mi exesposa y yo no tengo nada contra esto. Pero creo que falta también una ley para proteger al hombre en este sentido. Porque el hombre en la Ley María de la Peña va a estar tratado siempre injustamente, agredido por la ley, porque si él hace algo equivocado con la mujer va a ser castigado mientras que yo no conozco ninguna ley que dé un castigo a la mujer por el error que ella pueda cometer contra el hombre. No 
existe la Ley Mario de la Peña. (...) Aunque tampoco sé si, en caso que la hubiera, los hombres irían a comisaría a quejarse... sentirían vergüenza, creo.”

Otros hombres entrevistados también reivindicaron una ley propia que les protegiese de la violencia de las mujeres. Pero también dudaron si se atreverían a posicionarse como víctimas de sus mujeres.

\section{UNAS ÚLTIMAS PALABRAS.}

Tal como hemos mencionado anteriormente, este análisis de las atribuciones de sentido de hombres y mujeres, involucrados en situaciones de violencia doméstica contra la mujer, se une a tantos otros que acreditan que una mirada más minuciosa sobre ellas puede aportar visiones más complejas y adecuadas sobre las experiencias individuales y, a partir de esto, priorizar las políticas e intervenciones del Estado sobre el fenómeno. El análisis de los datos aquí expuestos sugiere una disputa entre hombres y mujeres por ocupar la primacía en la posición de víctima de la pareja en conflicto. Esto parece garantizar para las mujeres derechos de autonomía y alejamiento físico de los hombres, y para éstos una atenuación de sus penas, ya que no son exclusivamente los únicos que agreden en la pareja.

Según algunos autores franceses: (Eliacheff y Lariviere, 2007) estaríamos viviendo la "era de las víctimas". En este contexto, toda persona que sufre puede reivindicar para sí el papel de "víctima" y ser considerada como tal: el sufrimiento es una injusticia; no sufrir se convierte en un derecho. Las distintas percepciones que hombres y mujeres tienen sobre las dinámicas de violencia en la pareja, principalmente las relacionadas con las categorías aquí descritas y analizadas, deberán ser comparadas con otras investigaciones que estén comprometidas en contribuir a la creación y a la actualización de políticas publicas de lucha contra la violencia hacia las mujeres.

\section{BIBLIOGRAFÍA}

ANDERSON, D.K. and SAUNDERS, D.G. (2003): "Leaving an abusive partner: an empirical review of predictors, the process of leaving and psychological wellbeing", Trauma, Violence \& Abuse, 4,. 163-191.

DAVIS, K. (2008): "Intersectionality as buzzword. A sociology of science perspective on what makes a feminist theory sucessful."Feminist Theory, 9, 1, p. 67-85.

DEBERT, Guita Grin y GREGORI, Maria Filomena (2008): "Violência e gênero: novas propostas, velhos dilemas", Rev. bras. Ci. Soc., São Paulo, 23, 66. http://www.scielo.br/scielo.php?script=sci arttext\&pid=S010269092008000100011\&lng=en\&nrm=iso. $\quad$ 01/18/2012. 
ELIACHEFF, C. y LARIVIÈRE, D.S. (2007): Le temps des victimes,Paris, Éditions Albin Michel.

GREGORI, M.F.(1993): Cenas e queixas. Um estudo sobre mulheres, relações violentas e práticas feministas, São Paulo, Editora Paz e Terra.

(2010): "Violence and gender: Political paradoxes, conceptual shifts", Vibrant. Virtual Brazilian Anthropolog.y 2, 216-235. http://www.vibrant.org.br/ 06/20/2011.

MUSZKAT, S.(2003): "Novas práticas na abordagem de gênero e violência intrafamiliar, en: Muszkat, M. (ed.) Mediação de conflitos: pacificando e prevenindo a violência. São Paulo, Summus, 108-132.

PATEMAN, C. (1993): O contrato sexual, Rio de Janeiro, Paz e Terra.

SCHRAIBER, L.B. et al. (2009): "Violência de gênero no campo da saúde coletiva: conquistas e desafios", Ciência\&Saúde Coletiva, 13, 4, 1019-1027.

SCOTT, J. (1990): "Gênero: uma categoria útil de análise histórica". Revista Educação e realidade, Porto Alegre, 15, 2, 71-99.

SOARES, B.M. (2009): "Violência entre parceiros íntimos e criminalização da vida privada: ¿onde nos leva esse caminho?", en: Moraes, A.F. y Sorj, B. (eds). Gênero, violência e direitos na sociedade brasileira. Rio de Janeiro,7Letras, 144157.

(2012): "A "conflitualidade" conjugal e o paradigma da violência contra a mulher", en DILEMAS, Revista de Estudos de Conflito e Controle Social, $5,2,191-212$

SUÁREZ, M. y BANDEIRA, L. (2004): "A politização da violência contra a mulher e o fortalecimento da cidadania" en Bruschini y Unbehaum, S.G. (eds), Gênero, democracia e sociedade brasileira, São Paulo: Fundação Carlos Chagas/Editora $34,48-65$. 